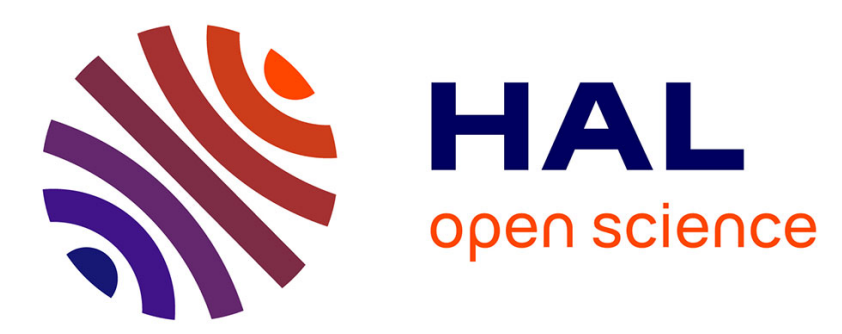

\title{
Effects of reading proficiency on embedded stem priming in primary school children
}

\author{
Elisabeth Beyersmann, Jonathan Grainger, Séverine Casalis, Johannes C. \\ Ziegler
}

\section{- To cite this version:}

Elisabeth Beyersmann, Jonathan Grainger, Séverine Casalis, Johannes C. Ziegler. Effects of reading proficiency on embedded stem priming in primary school children. Journal of Experimental Child Psychology, 2015, Journal of Experimental Child Psychology, 139, pp.115-126. 10.1016/j.jecp.2015.06.001 . hal-01432345

\section{HAL Id: hal-01432345 \\ https://hal.science/hal-01432345}

Submitted on 25 Jan 2021

HAL is a multi-disciplinary open access archive for the deposit and dissemination of scientific research documents, whether they are published or not. The documents may come from teaching and research institutions in France or abroad, or from public or private research centers.
L'archive ouverte pluridisciplinaire HAL, est destinée au dépôt et à la diffusion de documents scientifiques de niveau recherche, publiés ou non, émanant des établissements d'enseignement et de recherche français ou étrangers, des laboratoires publics ou privés. 
Effects of reading proficiency on embedded stem priming in primary school children

\author{
Elisabeth Beyersmann ${ }^{1}$, Jonathan Grainger ${ }^{1}$, Séverine Casalis ${ }^{2}, \&$ Johannes C. Ziegler ${ }^{1}$ \\ ${ }^{1}$ Laboratoire de Psychologie Cognitive, Aix-Marseille Université and Centre National de la \\ Recherche Scientifique, Marseille \\ ${ }^{2}$ Laboratoire URECA (EA 1059), Université Lille Nord de France
}

Address for correspondence:

Elisabeth Beyersmann,

Laboratoire de Psychologie Cognitive,

Aix-Marseille Université

3, place Victor Hugo

Bat. 9, Case D

13331 Marseille Cedex 1, France

Tel: +33777283814

Email: lisi.beyersmann@gmail.com

Short title: Embedded stem priming

Words: 4806 
Abstract

Prior evidence from masked morphological priming has revealed conflicting findings regarding the acquisition of morpho-orthographic segmentation mechanisms in developing readers. Here, we examined changes in masked morphological priming across grade within a large sample of French primary school children $(n=191$, grades $2-5)$ and how these effects are modulated by individual differences in reading proficiency, spelling proficiency, and morphological awareness. Target words were preceded by either (i) a suffixed word prime (e.g., tristesse-TRISTE), (ii) a suffixed nonword prime (e.g., tristerie-TRISTE), (iii) a nonsuffixed nonword prime (e.g., tristald-TRISTE), or (iv) an unrelated prime (e.g., directionTRISTE), using very short prime durations $(50 \mathrm{~ms})$. Moreover, a frequency manipulation was included for suffixes and non-suffixes. The results revealed robust suffixed word priming across all children, independently of grade and proficiency. On the other hand, priming in the suffixed and non-suffixed nonword conditions was modulated by reading proficiency, with high proficiency children showing facilitation and low proficiency children showing inhibition. The effects of suffix and non-suffix frequency were modulated by grade, with the effects decreasing as grade increased. None of the observed priming effects were modulated by grade, spelling proficiency or morphological awareness. The results suggest that reading proficiency is an important predictor for embedded stem activation mechanisms in primary school children, which we discuss in the context of recent theories of morphological processing. $($ words $=220, \max =250)$

Keywords: morphological processing, embedded stem priming, reading development, reading proficiency, masked priming 


\section{Acknowledgments}

This project was supported by a postdoctoral grant from the Fyssen Foundation to Elisabeth Beyersmann and a grant from the European Research Council (ERC grant 230313) to Jonathan Grainger. This research was carried out within the Labex BLRI (ANR-11-LABX0036) and, as such, has benefited from support from the French government, managed by the French National Agency for Research (ANR), Investments of the Future A*MIDEX (ANR11-IDEX-0001-02). We also thank Clelie Bigo, Maeva Veber and Marcia Becu for help with participant recruitment and testing. 
Over the past decades, much research has been dedicated to understanding how morphemes are processed in the skilled reading system. Most of this research has used the masked primed lexical decision task in combination with behavioral and sometimes electrophysiological measures. This research has generated important insights into the mechanisms and the time-course of morphological processing in adults (e.g., Beyersmann, Iakimova, Ziegler, \& Colé, 2014; Diependaele, Sandra, \& Grainger, 2009; Morris, Frank, Grainger, \& Holcomb, 2007; for a review, see Rastle \& Davis, 2008). However, only recently scientists have begun to explore the development of such processes in children (e.g., Beyersmann, Castles, \& Coltheart, 2012; Casalis, Dusautoir, Colé, \& Ducrot, 2009; Quémart, Casalis, \& Colé, 2011). We first outline the key milestones from morphological processing research in adults, followed by a summary of the related evidence from reading development.

Morphemes are the smallest meaningful entities that words are composed of. Based on a growing body of psycholinguistic evidence in adults, it is now known that the activation of morphemes is a rapid, highly automatized process which does not necessarily require the involvement of semantics. This now broadly accepted view primarily originates from the results reported in numerous masked morphological priming studies, across different languages, showing that not only words with a true morphological structure (e.g., farm-er), but also words with a pseudo-morphological structure (e.g., corn-er) produce priming of the stem target (e.g., farm, corn), even if presented with very short (40-50 ms) prime durations (for a review, see Rastle \& Davis, 2008). Since the meaning of pseudo-affixed words like corner cannot be derived from the meaning of its constituents corn and $e r$, it has been argued that the activation of the embedded stem corn must be due to a semantically blind "morphoorthographic" decomposition process.

In addition to the evidence for morpho-orthographic processing, masked morphological priming studies in adults have further revealed that truly suffixed words tend to produce slightly stronger stem-target priming (e.g., farmer-FARM) than pseudo-suffixed 
words (e.g., corner-CORN), particularly when the prime is partially or fully visible (e.g., Diependaele et al., 2009; Feldman, O'Connor, \& Moscoso del Prado Martin, 2009). These findings suggest that the early morpho-orthographic processing stages are followed by a later "morpho-semantic" processing stage, by which truly affixed words (but not pseudo-affixed words) are segmented into semantically defined morphemic units.

Critically, the data discussed above have recently been complemented by masked priming studies using morphologically structured nonword primes. Longtin and Meunier (2005) were the first to report priming with suffixed (e.g., rapidifier-RAPIDE) but not with non-suffixed nonwords (e.g., rapiduit-RAPIDE). However, recent morphological priming studies have found results that partially deviate from the Longtin and Meunier pattern (Beyersmann, Casalis, Ziegler, \& Grainger, 2014; Morris, Porter, Grainger, \& Holcomb, 2011). Beyersmann et al. (2014) examined lexical decision times to target words preceded by four different types of primes: a suffixed word prime (e.g., tristesse-TRISTE), a suffixed nonword prime (e.g., tristerie-TRISTE), a non-suffixed nonword prime (e.g., tristald-TRISTE) or an unrelated prime (e.g., direction-TRISTE). The results revealed robust and equal priming in the two suffixed conditions across all participants, suggesting that not only suffixed real words, but also suffixed nonwords are rapidly decomposed into morpho-orthographic subunits at early stages during visual word recognition. This thus demonstrates that morphoorthographic decomposition mechanisms apply even in a nonword context in which the semantic stem-affix relationship is entirely non-interpretable.

Most importantly however, Beyersmann et al.'s findings revealed that priming in the non-suffixed nonword condition was modulated by individual language proficiency. While high proficiency adults showed as much priming in the non-suffixed condition as in the other two conditions, low proficiency adults did not show any evidence for non-suffixed priming. The priming effect observed in the non-suffixed nonword condition is of particular relevance, as it suggests that high proficiency individuals rapidly activate embedded stems at early stages 
during visual word recognition, even in the absence of an affix. Hence, these nonword priming data suggest that affix-stripping in adult readers is complemented, and possibly even substituted by embedded stem activation mechanisms.

Prior evidence from lexical decision indicates that children already use morphological structure from as early as seven years old (Lázaro, Camacho, \& Burani, 2013; Perdijk, Schreuder, Baayen, \& Verhoeven, 2012). However, recent findings from masked morphological priming suggest that morpho-orthographic decomposition is quite a lateoccurring milestone in reading acquisition (Beyersmann et al., 2012). One hypothesis that has been put forward is that children first learn to link the meanings of related whole words (e.g. a painter is someone who paints, a teacher is someone who teaches, etc.), which eventually results in a form-based morphological segmentation mechanism which is applied to every letter string with the mere appearance of morphological complexity (e.g., moth-er, numb-er, flow-er, etc.). Critically, previous studies using the masked priming paradigm to examine the role of morphological knowledge during reading development has revealed conflicting findings. Quémart, Casalis and Colé (2011) tested French third, fifth and seventh graders and found evidence for true morphological priming (e.g., farmer-FARM) and pseudomorphological priming (e.g., corner-CORN) across all age groups. The findings thus replicate the pattern standardly observed in adults, showing that French children rapidly decompose complex words into semantically blind morpho-orthographic subunits as early as grade 3 . However, Beyersmann, Castles and Coltheart (2012), observed a different pattern in two groups of English speaking grade 3 and grade 5 children. Masked primes were presented for $50 \mathrm{~ms}$ and priming effects were found only for prime-target pairs sharing a true morphological relationship (farmer-FARM), but not in the pseudo-morphological condition (corner-CORN). Beyersmann et al.'s results thus demonstrate that English-speaking grade 3 and 5 children only produce priming when prime and target are semantically related, 
suggesting that they have not yet acquired abstract morphemic representation which are thought to be essential for the automatic segmentation into morpho-orthographic units.

One possible reason for these divergent findings is the fact, first pointed out by Baayen, Milin, Filipovic Durdevic, Hendrix, and Marelli (2011), that prime words previously tested in the opaque/pseudo-morphological priming condition vary in the extent to which the suffix conveys its regular meaning. For example, as Baayen and colleagues (2011) pointed out, the etymological origin of archer ("someone who wields a bow") is Latin arcus (bow, arc), which is similar in structure to a denominal formation such as trucker ("someone who drives a truck"). On the other hand, a word like corner is clearly pseudo-suffixed, because the meaning of corner cannot be derived from the meaning of corn and er. In the present study, we avoided this problem by using complex nonword primes to test for morpho-orthographic segmentation in children, as in the prior research with adults summarized above (Beyersmann, Casalis, et al., 2014). It is also possible that morphological parsing mechanisms in French and English are acquired at different speeds. French is morphologically more productive than English, and French children have been found to outperform English children in morphological knowledge (e.g., Duncan, Casalis, \& Colé, 2009). It is therefore possible that French children begin to automatize morphological processing at an earlier age than English children, which would explain the absence of morpho-orthographic priming in Englishspeaking readers. A third fundamental confound within the assessment of morphological processing mechanisms in developing readers may be that children within the same age/grade group vary largely in their individual proficiencies in reading, spelling and morphology. For instance, some children in the last years of primary school have reading proficiency levels that are comparable to those of children in the lower grades and vice versa. One solution is to exclude children with reading problems who fall outside the expected proficiency range per grade level. However, this approach does not only result in the loss of valuable statistical power, but also narrows the analyses down to grade-level comparisons, rather than using more 
fine-tuned continuous proficiency measures irrespective of grade. Therefore, in order to more clearly capture the relationship between the acquisition of morpho-orthographic parsing mechanisms and the development of reading skills, it is essential to explore individual differences in reading proficiency continuously rather than analyze children per grade. Similarly, individual differences in spelling proficiency and morphological awareness may present confounds in previous developmental priming studies. However, masked priming evidence in children is sparse and based on rather small participant samples from selected age groups (e.g., Beyersmann et al., 2012; Quémart et al., 2011). Thus, the role of individual proficiency differences during the acquisition of morphological processing mechanisms is still not clear.

The goal of our present study was to examine the early processing of embedded stems and affixes within the developing reading system. Here, we tested a large sample of French primary school children $(n=191$, from grades 2 to 5$)$ with varying levels of reading proficiency, spelling proficiency, and morphological awareness, in order to explore whether or not these individual differences modulate morphological priming. We replicated the design previously used in adults (Beyersmann, Casalis, et al., 2014), comparing target words preceded by (i) a suffixed word prime (e.g., tristesse-TRISTE), (ii) a suffixed nonword prime (e.g., tristerie-TRISTE), (iii) a non-suffixed nonword prime (e.g., tristald-TRISTE) or (iv) an unrelated prime (e.g., direction-TRISTE), using very short prime durations (50 ms). Critically, in contrast to previous developmental work (Beyersmann et al., 2012; Quémart et al., 2011), we used the exact same targets in all four prime conditions, to rule out that differences across conditions might be due to uncontrolled differences between target words.

If affixes form the primary recognition units in the developing reading system, we would expect significant priming in the suffixed word and suffixed nonword conditions, but not in the non-suffixed condition. If, however, children also draw upon an embedded stem activation mechanism during the early stages of visual word recognition, we would expect 
significant priming in all three priming conditions (including the non-suffixed condition). If morpho-orthographic segmentation mechanisms are acquired over the course of primary school, we would expect to see an increase of suffixed word and suffixed nonword priming across grades. If embedded stem activation mechanisms are acquired over the course of primary school, we would expect to see an increase in all three priming conditions across grades. Moreover, if morphological priming is modulated by children's performance in reading, spelling, and morphological awareness tasks, we would expect that the magnitudes of suffixed nonword and non-suffixed nonword priming should vary depending on individual differences in these scores. In addition, given that previous studies in developing readers have unambiguously reported evidence for true morphological priming effects (e.g., Beyersmann et al., 2012; Quémart et al., 2011), we expected that priming in the suffixed word condition should be robust across all children, independently of proficiency.

Finally, we adapted a further feature of the Beyersmann et al. materials, where suffixes and non-suffixes were divided into a high and a low frequency condition. If it is true that affixes form morpho-orthographic units in the developing reading system (e.g., Quémart et al., 2011), we would expect more priming for primes with high-frequency suffixes than low-frequency suffixes, but no difference between high- and low-frequency non-suffixes. If however, suffixes and non-suffixes have a comparable status during the first years of reading development, we would predict that high ending frequency should boost the activation of embedded target words, independently of the morphemic status of the ending-string.

\section{Method}

\section{Participants}

One hundred ninety-one children in grades 2-5 were recruited from a primary school in Lille and Arras, northern France (46 second graders, 48 third graders, 49 fourth graders, 
and 48 fifth graders). The mean participant age per grade was 7.7 years in Grade 2, 8.7 in

Grade 3, 9.6 in Grade 4, and 10.6 in Grade 5. All were French native speakers with normal or corrected-to-normal vision. Parental consent was obtained prior to the testing. Children with a history of dyslexia and/or language impairment were excluded. No child was affected by hearing loss.

\section{Materials}

The materials were identical to the ones used in Beyersmann, et al. (2014). We first confirmed that the 50 word targets and suffixed word primes, originally selected from the adult corpus Lexique (New, Pallier, Brysbaert, \& Ferrand, 2004), were also present in a lexical database for grade 1 children (MANULEX; Lété, Sprenger-Charolles, \& Colé, 2004). Each target was preceded by a suffixed word prime (tristesse-TRISTE [sadness-SAD]), a suffixed nonword prime (tristerie-TRISTE [sadation-SAD]), a non-suffixed nonword prime (tristald-TRISTE [sadald-SAD]), and an unrelated prime (direction-TRISTE [direction-SAD]). Suffixed word primes were real words comprising stem (triste) and suffix (esse). Suffixed nonword primes were created using the same stem, but a different suffix of comparable frequency (rie), such that the whole letter string was not a word. Non-suffixed nonword primes were created by combining the stem with a non-morphemic ending (ald). Unrelated primes were suffixed words and all letter different from the target. All nonwords were orthographically legal and pronounceable. The four prime conditions were matched on length (for a full list of materials, see Beyersmann et al., 2014, Appendix 1).

Trials were divided into two subsets: one where primes comprised high-frequency suffixes (-ette, -ier, -eur, -ion, and -age) and one where primes comprised low-frequency suffixes (-esse, -oir, -ade, -ien, and -rie). Non-suffixed nonwords were created using five high-frequency (-nie, -ire, -ide, -ert, and -use) and five low-frequency non-morphemic endings (-uor, -ald, -abe, -uto, and -bli). String frequency was calculated based on the 
number of words in the Manulex database (Lété et al., 2004) which contained the given letter sequence in final position. Low frequency non-suffixes had a maximum frequency of 10 (mean: 4.2), and high frequency non-suffixes a minimum frequency of 40 (mean: 151.8). Low frequency suffixes had a maximum frequency of 170 (mean: 100.6) and high frequency suffixes a minimum frequency of 240 (mean: 402.0). Suffixed words and nonwords used the same suffixes, but with different stems. High and low frequency conditions were matched on length, frequency, suffix length and nonmorphemic ending length. For the purpose of the lexical decision task, 50 nonword targets (identical to the Set 2 nonwords in Beyersmann et al., 2014) were included and matched to the word targets on length.

\section{Procedure}

The procedure was identical to the one used in adults (Beyersmann et al., 2014). Stimuli were presented in the centre of a computer screen, using DMDX (Forster \& Forster, 2003). Each trial consisted of a 500-ms forward mask of hash keys, then a 50-ms prime in lowercase, then the uppercase target. The target remained present until the response or until 3 seconds had elapsed. Children were instructed to respond as quickly and accurately as possible. The experiment took between 3-6 minutes per participant.

\section{Measures of individual differences}

Upon completion of the masked primed lexical decision task, each child was assessed with a spelling proficiency test, a reading proficiency test, and a morphological awareness test. The morphological awareness task was used to measure children's awareness of morphological structures during spoken language processing. The reading and spelling tasks were used as two measures for children's proficiency in processing printed words. 
The 'Corbeau' subtest was used to assess spelling proficiency in Grade 3-5 children (Chevrie-Muller, Maillart, Simon, \& Fournier, 2010). For each child, three different scores were obtained: (i) number of responses with correct phonetic form (e.g. oizo instead of oiseau), (ii) number of responses which are related existing lexical entries (e.g. oiseaux instead of oiseau; rendu instead of rendus), and (iii) number of correct responses. Spelling proficiency in Grade 2 children was examined based on a different dictation test ("dictée de phrases”), adapted for children with little spelling experience (Chevrie-Muller et al., 2010).

\section{Reading proficiency}

The 'Alouette' was used to asses children's reading proficiency (Lefavrais, 1974, 2005). Children were asked to read aloud a text of 265 words for which both reading accuracy (l'indice de precision) and speed (l'indice de vitesse; how many words are read within 3 minutes) were measured and evaluated based on the revised Alouette 2005 scoring system.

\section{Morphological awareness}

Morphological awareness was assessed with a test developed by Casalis, Colé and Sopo (2004), consisting of three different spoken language tasks: two sentence completion tasks and an oddity task. In the sentence completion tasks, children were asked to produce a real affixed word (e.g. "Someone who works on a farm is a ...") or a pseudo-affixed word (e.g. "Someone who works in a birk is a ..."). In the oddity task, children were presented with 4 orthographically related words, amongst which only 3 shared the same morphemic stem (e.g. turn, turning, turner, turnip). The score was the number of correct responses in each task.

\section{Results}


Lexical decisions to word targets were analyzed as follows. Incorrect responses were removed from the RT analysis (11.4\% of all data). Outliers below $200 \mathrm{~ms}$ were removed, which led to the removal of $0.03 \%$ of the data. $1 /$ RTs were calculated for each participant to correct for RT distribution skews and used throughout the analyses. Untransformed RTs and error rates are presented in Table 1.

\section{-Table 1-}

We used linear mixed-effect model modelling to perform the main analyses (Baayen, 2008; Baayen, Davidson, \& Bates, 2008). Fixed and random effects were only included if they significantly improved the model's fit in a backward stepwise model selection procedure. Models were selected using chi-squared log-likelihood ratio tests with regular maximum likelihood parameter estimation. Trial order was included to control for longitudinal task effects such as fatigue or habituation. To assess whether the obtained effects were modulated by individual differences of reading proficiency, spelling proficiency, or morphological awareness, the scores from the spelling dictation, reading aloud and morphological awareness tests were standardized for each grade. Composite measures were calculated by adding the standard scores of the subtests. Factor grade was included to explore the development of morphological segmentation across primary school grades. Ending-frequency was examined as a continuous variable. Finally, to rule out that any of the observed effects were due to differences in stem frequency (i.e. target frequency), we included this factor as a covariate in the analyses.

A linear mixed-effects model as implemented in the lme4 package (Bates, Maechler, Bolker, \& Walker, 2014) in the statistical software R (Version 3.0.3;

RDevelopmentCoreTeam, 2008) was fitted with eight fixed effect factors (primetype: suffixed-word, suffixed-nonword, nonsuffixed-nonword, unrelated word; ending-frequency; reading proficiency; spelling proficiency; morphological awareness; grade; stem-frequency; trial order), their interactions, and two random effects factors (random intercepts for subjects 
and items). P-values were determined using the package lmerTest (Kuznetsova, Brockhoff, \& Christensen, 2014). RT analyses revealed a significant priming effect in the suffixed word condition $(t=4.17, p<.001)$, in the suffixed nonword condition $(t=2.28, p=.022)$, and a marginally significant priming effect in the non-suffixed nonword condition $(t=1.85, p=.065)$. Priming in the suffixed word condition was significantly larger than priming in the nonsuffixed nonword condition $(t=2.33, p=.020)$, and marginally significantly larger than in the suffixed nonword condition $(t=1.88, p=.060)$. Although there was a significant main effect of grade $(t=8.47, p<.001)$, grade did not modulate priming (see Figure 1, left panel).

-Figure 1-

Ending-frequency, stem-frequency, spelling proficiency and morphological awareness did not significantly improve the model's fit and were therefore excluded from the analyses. Interestingly however, the results revealed that while priming in the suffixed word condition (relative to the unrelated control condition) was not modulated by reading proficiency $(t=1.63$, $p=.102$ ), reading proficiency did modulate priming in the suffixed nonword condition and nonsuffixed nonword condition $(t=3.56, p<.001 ; t=2.62, p=.009)$, showing that there was an inhibitory effect for children with low levels of reading proficiency, but a facilitatory effect for children with high levels of reading proficiency (see Figure 1, right panel).

Error analyses followed the same logic as the RT analyses. We applied a binomial variance assumption to the trial-level binary data using the function glmer as part of the Rpackage $l m e 4$. There was a significant effect of grade $(z=.5 .89, p<.001)$, showing that errors decreased with increasing grade level. There was a significant effect of reading proficiency $(z=5.67, p<.001)$, showing that errors decreased with increasing proficiency. No other effects were significant. 


\section{Discussion}

In the present study, we tested a large sample of French children in grades 2-5 of primary education in order to a) investigate the development of morpho-orthographic and morpho-semantic processing mechanisms across grades and b) examine changes in morphoorthographic and morpho-semantic processing as a function of individual differences in reading, spelling and morphological proficiency in beginning readers. Using the masked priming paradigm combined with a lexical decision task, priming in a truly suffixed condition (e.g., tristesse-TRISTE) was compared to a suffixed nonword (e.g., tristerie-TRISTE) and a non-suffixed nonword condition (e.g., tristald-TRISTE), using the same targets across conditions. Relative to an unrelated prime condition, robust suffixed word priming was observed across all children, independently of grade and proficiency. This suffixed priming effect was significantly larger than the priming effects observed in the suffixed nonword and non-suffixed nonword conditions, suggesting that the semantic interpretability of morphologically complex letter strings helps the segmentation into stem and affix. These results are consistent with previous developmental work from French and English-speaking primary school children (e.g., Beyersmann et al., 2012; Quémart et al., 2011).

Interestingly, priming in the suffixed and non-suffixed nonword conditions did not change as a function of grade. Moreover, there was no difference between the magnitude of suffixed and non-suffixed nonword priming (see comparable trajectories of both conditions in Figure 1, left panel). Our data thus do not provide evidence for morpho-orthographic segmentation, but rather speak in favor of children using embedded stem activation mechanisms (Beyersmann, Casalis, et al., 2014) during early morphological processing (we return to this point in more detail below). Most importantly, however, our present data suggest that priming did not change as a function of grade, as thus provide no evidence for developmental changes in morpho-orthographic and morpho-semantic processing across 
primary school, at least not when primes are presented subliminally (c.f., Ziegler, Bertrand, Lété, \& Grainger, 2014).

Our second key finding is that priming in the suffixed and non-suffixed nonword conditions was modulated by individual differences in reading proficiency (see Figure 1, right panel). While facilitatory priming effects were observed for high proficiency children, low proficiency children showed an inhibitory priming effect. These results suggest that high proficiency children benefit from the activation of embedded words, independently of whether they occur in combination with a real suffix (rie) or a non-suffix (ald). Children with higher levels of reading proficiency would be more expert in mapping sublexical orthography onto whole-word orthographic representations, and this would facilitate the activation of the embedded target word during prime processing (see also Beyersmann, Casalis, et al., 2014, for related evidence from adults). That is, letters in the prime stimulus activate whole-word orthographic representations even when the orthographic overlap between prime and target is only partial (Ziegler, Bertrand, et al., 2014). Higher levels of efficiency in such whole-word processing lead to stronger priming effects from embedded stems, independently of whether the stem is accompanied by an affix or not.

The absence of embedded stem priming effects in previous developmental priming studies (e.g., Beyersmann et al., 2012; Quémart et al., 2011) is likely to be due to the fact that stems were embedded in strings which themselves are real words (e.g., cashew-CASH). The simultaneous activation of the lexical representations of cash and cashew generates competition between the two lexical entries, and prevents stem-target priming (for similar reasoning, see Beyersmann, Casalis, et al., 2014).

What might be the cause of the inhibitory priming effect seen with low proficiency children in the suffixed nonword (tristerie-TRISTE) and non-suffixed nonword conditions (tristald-TRISTE)? This result suggests that the nonword primes (tristerie/tristald) generated some form of competitive process that affected activation of the embedded target word 
(triste). This competition could operate as children attempt to acquire novel lexical representations using orthographic learning (see Ziegler, Perry, \& Zorzi, 2014). Successful creation of a new representation for a novel orthographic form (e.g., tristerie, tristald) would require suppressing the activation of orthographically similar known words (e.g., tristesse, triste, etc.), and this would result in slower responses to the embedded target word following a related nonword prime. These competitive processes would be countered in children with higher levels of reading proficiency by the nonword prime activating more strongly the embedded stem.

It is also important to note that in the present study we found no difference between the suffixed and non-suffixed nonword conditions, whatever the grade or the reading proficiency of the children. In the Beyersmann, Casalis, et al. (2014) study, low proficiency adults showed priming with suffixed but not with non-suffixed nonwords. Beyersmann and colleagues argued that morpho-orthographic segmentation processes, such as affix-stripping, led to enhanced activation of embedded stems during the processing of suffixed nonword primes by low proficiency participants. That is, the drop in efficiency in processing wholeword orthographic information (including embedded words) is compensated by morphoorthographic segmentation processes. The present results suggest that, in primary school children, independent of their reading proficiency, morpho-orthographic processing is not yet sufficiently rapid and/or automatized in order to affect subliminal (i.e., automatic) priming. In contrast, our results suggest that embedded stems function as lexical representations, not as morpho-orthographic representations, which can be activated subliminally (i.e., automatically) during the process of learning to read. Morpho-orthographic segmentation mechanisms appear to be acquired quite late during reading development, and are likely to emerge at later stages throughout middle-school or high-school. We hypothesise that once morpho-orthographic segmentation has been incorporated in the reading system, it will gradually be used to increasingly compensate for lower proficiency in using lexical whole- 
word representations, as it has been shown to be the case in adults (Beyersmann, Casalis, et al., 2014). 


\section{References}

Baayen, R. H. (2008). Analyzing linguistic data: A practical introduction to statistics using $R$. Cambridge: Cambridge University Press.

Baayen, R. H., Davidson, D. J., \& Bates, D. M. (2008). Mixed-effects modeling with crossed random effects for subjects and items. Journal of Memory and Language, 59, 390412.

Baayen, R. H., Milin, P., Filipovic Durdevic, D., Hendrix, P., \& Marelli, M. (2011). An amorphous model for morphological processing in visual comprehension based on naive discriminative learning. Psychological Review, 118, 438-482.

Bates, D., Maechler, M., Bolker, B., \& Walker, S. (2014). lme4: Linear mixed-effects models using Eigen and S4. R package version 1.1-5. http://CRAN.Rproject.org/package=lme4.

Beyersmann, E., Casalis, S., Ziegler, J. C., \& Grainger, J. (2014). Language proficiency and morpho-orthographic segmentation. Psychonomic Bulletin \& Review, Advance online publication.

Beyersmann, E., Castles, A., \& Coltheart, M. (2012). Morphological processing during visual word recognition in developing readers: Evidence from masked priming. The Quarterly Journal of Experimental Psychology, 65(7), 1306-1326.

Beyersmann, E., Iakimova, G., Ziegler, J. C., \& Colé, P. (2014). Semantic processingduringmorphologicalpriming: An ERPstudy. Brain Research, 1579, 45-55.

Casalis, S., Colé, P., \& Sopo, D. (2004). Morphological awareness and dyslexia. Annals of Dyslexia, 54(1), 114-138.

Casalis, S., Dusautoir, M., Colé, P., \& Ducrot, S. (2009). Morphological effects in children word reading: A priming study in fourth graders. British Journal of Developmental Psychology, 27, 761-766.

Chevrie-Muller, C., Maillart, C., Simon, A. M., \& Fournier, S. (2010). Langage oral, langage écrit, mémoire, Attention, 2ème édition : L2MA-2. Paris: Edition du centre de psychologie appliquée (ECPA).

Diependaele, K., Sandra, D., \& Grainger, J. (2009). Semantic transparency and masked morphological priming: The case of prefixed words. Memory \& Cognition, 37, 895908.

Duncan, L. G., Casalis, S., \& Colé, P. (2009). Early metalinguistic awareness of derivational morphology: Observations from a comparison of English and French. Applied Psycholinguistics, 30(3), 405-440.

Feldman, L. B., O'Connor, P. A., \& Moscoso del Prado Martin, F. (2009). Early morphological processing is morpho-semantic and not simply morpho-orthographic: A violation of form-then-meaning accounts of word recognition. Psychonomic Bulletin \& Review, 16(4), 684-691.

Forster, K. I., \& Forster, J. C. (2003). DMDX: A Windows display program with millisecond accuracy. Behavior Research Methods, Instruments, \& Computers, 35(1), 116-124.

Kuznetsova, A., Brockhoff, P. B., \& Christensen, R. H. B. (2014). lmerTest: Tests for random and fixed effects for linear mixed effect models (lmer objects of lme4 package): $\mathrm{R}$ package version 2.0-6. http://CRAN.R-project.org/package=lmerTest.

Lázaro, M., Camacho, L., \& Burani, C. (2013). Morphological processing in reading disabled and skilled Spanish children. Dyslexia, 19(3), 178-188.

Lefavrais, P. (1974). Test de l'Alouette. Paris: Editions du Centre de Psychologie Appliquée.

Lefavrais, P. (2005). L'Alouette-R. Paris: Les Editions du Centre de Psychologie Appliquée. 
Lété, B., Sprenger-Charolles, L., \& Colé, P. (2004). MANULEX: A grade-level lexical database from French elementary school readers. Behavior Research Methods, Instruments, \& Computers, 1(36), 156-166.

Longtin, C. M., \& Meunier, F. (2005). Morphological decomposition in early visual word processing. Journal of Memory and Language, 53, 26-41.

Morris, J., Frank, T., Grainger, J., \& Holcomb, P. J. (2007). Semantic transparency and masked morphological priming: an ERP investigation. Psychophysiology, 44, 506521.

Morris, J., Porter, J. H., Grainger, J., \& Holcomb, P. J. (2011). Effects of lexical status and morphological complexity in masked priming: An ERP study. Language and Cognitive Processes, 26(4-6), 558-599.

New, B., Pallier, C., Brysbaert, M., \& Ferrand, L. (2004). Lexique 2: A new French lexical database. Behavior Research Methods, Instruments, \& Computers, 36, 516-524.

Perdijk, K., Schreuder, R., Baayen, R. H., \& Verhoeven, L. (2012). Effects of morphological Family Size for young readers. British Journal of Developmental Psychology, 30(3), 432-445.

Quémart, P., Casalis, S., \& Colé, P. (2011). The role of form and meaning in the processing of written morphology: A priming study in French developing readers. Journal of Experimental Child Psychology, 109, 478-496.

Rastle, K., \& Davis, M. H. (2008). Morphological decomposition based on the analysis of orthography. Language \& Cognitive Processes, 23, 942-971.

RDevelopmentCoreTeam. (2008). $R$ : A language and environment for statistical computing: $\mathrm{R}$ package version 1.1-5. http://CRAN.R-project.org/package=lme4.

Ziegler, J. C., Bertrand, D., Lété, B., \& Grainger, J. (2014). Orthographic and phonological contributions to reading development: Tracking developmental trajectories using masked priming. Developmental Psychology, 50(4), 1026-1036.

Ziegler, J. C., Perry, C., \& Zorzi, M. (2014). Modelling reading development through phonological decoding and self-teaching: Implications for dyslexia. Philosophical Transactions of the Royal Society B, 369(20120397), 1-9. 
Table 1

Table 1. Reaction times (in ms) and error rates (in \%), averaged across items and participants.

Standard deviations are presented in parentheses. Reading age level is calculated based on the Alouette reading proficiency test (Lefavrais, 2005).

\begin{tabular}{|c|c|c|c|c|c|}
\hline $\begin{array}{l}\text { Reading } \\
\text { age level }\end{array}$ & $\begin{array}{l}\text { Suffixed } \\
\text { word }\end{array}$ & $\begin{array}{l}\text { Suffixed } \\
\text { nonword }\end{array}$ & $\begin{array}{l}\text { Non-suffixed } \\
\text { nonword }\end{array}$ & Unrelated & $\begin{array}{l}\text { Number of } \\
\text { children }\end{array}$ \\
\hline \multicolumn{6}{|c|}{ Reaction times } \\
\hline Grade 1 & $1451(405)$ & $1748(477)$ & $1721(371)$ & $1576(505)$ & 4 \\
\hline Grade 2 & $1390(377)$ & $1412(404)$ & $1410(359)$ & $1400(377)$ & 45 \\
\hline Grade 3 & $1086(255)$ & $1109(283)$ & $1112(279)$ & $1166(306)$ & 45 \\
\hline Grade 4 & $961(184)$ & $971(159)$ & $967(158)$ & $982(178)$ & 31 \\
\hline Grade 5 & $941(178)$ & $925(168)$ & $935(161)$ & $968(190)$ & 35 \\
\hline Grade 6 & $933(167)$ & 977 (187) & $952(177)$ & $957(143)$ & 21 \\
\hline Grade 7 & $808(158)$ & $801(141)$ & $860(211)$ & 887 (117) & 8 \\
\hline Grade 8 & $674(161)$ & $681(97)$ & $685(98)$ & $716(123)$ & 2 \\
\hline \multicolumn{6}{|c|}{ Error rates } \\
\hline Grade 1 & $45.0(6.0)$ & $40.5(9.5)$ & $40.0(10.7)$ & $48.0(5.1)$ & 4 \\
\hline Grade 2 & $32.0(18.0)$ & $37.2(12.9)$ & $33.6(17.5)$ & $32.5(16.3)$ & 45 \\
\hline Grade 3 & $22.4(18.9)$ & $24.0(17.8)$ & $21.2(18.8)$ & $24.9(19.0)$ & 45 \\
\hline Grade 4 & $20.7(17.3)$ & $20.1(18.4)$ & $16.8(15.8)$ & $18.4(17.8)$ & 31 \\
\hline Grade 5 & $16.0(16.8)$ & $18.0(19.0)$ & $15.2(18.0)$ & $16.6(18.6)$ & 35 \\
\hline Grade 6 & $13.6(14.7)$ & $14.3(17.5)$ & $17.3(17.8)$ & $14.9(16.5)$ & 21 \\
\hline Grade 7 & $24.5(16.0)$ & $10.7(14.7)$ & $19.5(16.5)$ & $5.1(14.3)$ & 8 \\
\hline Grade 8 & $15.1(21.3)$ & $18.8(26.6)$ & $23.4(33.1)$ & $20.2(28.6)$ & 2 \\
\hline
\end{tabular}


Figure 1
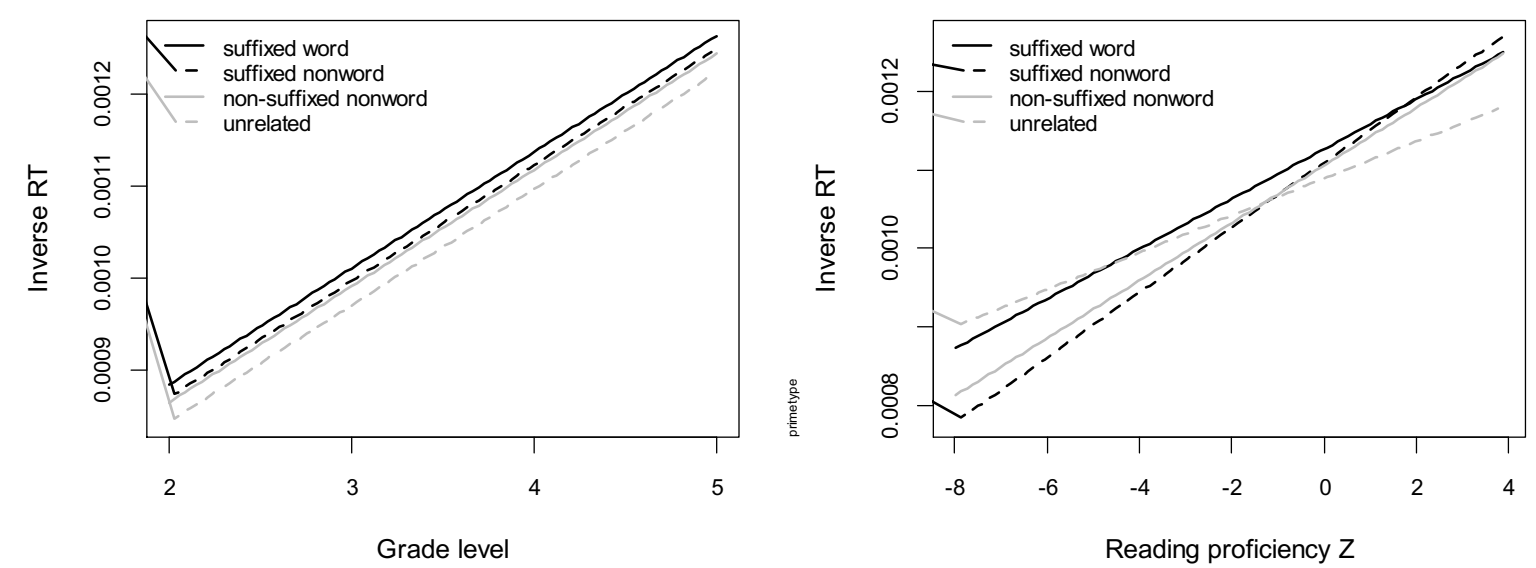


\section{Figure Legends}

Figure 1. Inverse reaction times to targets preceded by unrelated, suffixed word, suffixed nonword and non-suffixed nonword primes, as a function of grade (left panel) and reading proficiency (right panel). 